\title{
Comparison between radiotherapy and transoral laser microsurgery treatments in early-stages of glottis cancer: A five-year follow-up study.
}

\author{
Javier Santabárbara
}

Department of Microbiology, Pediatrics, Radiology and Public Health, Universidad de Zaraǵoza, Zaragoza, Spain.

Instituto de Investigación Sanitaria de Aragón (IIS Aragón), Zaragoza, Spain. Centro de Investigación Biomédica en Red de Salud Mental (CIBERSAM). Ministry of Science and Innovation, Madrid, Spain.

Key words: Glottis squamous cell carcinoma; early stages; radiotherapy; transoral laser microsurgery; recurrence; survival.

\begin{abstract}
This study was aimed to compare the recurrence-free survival rate among patients with Stage I or II of squamous carcinoma of the glottis treated with transoral laser microsurgery or radiotherapy, at a Spanish tertiary hospital. Between January 2004 and December 2016, data were collected from 120 patients diagnosed with stages I or II of squamous cell carcinoma of the larynx located in the glottis. Ninety-one patients were treated with transoral laser microsurgery and 29 patients received radiotherapy. The recurrence-free survival was studied during the first five years after the primary treatment. Kaplan-Meier survival curves and Cox regression models were performed. The cumulative incidence of glottis cancer recurrence was $62.6 \%$ in those treated with transoral laser microsurgery and $65.5 \%$ in those treated with radiotherapy. This led to an absolute risk reduction of $2.9 \%$ (95\% CI: -17.1 to 22.8 ), and a number needed to treat of 35 patients. Those patients who received transoral laser microsurgery had a $17 \%$ lower risk of recurrence of glottis eancer than those treated with radiotherapy (hazard ratio, $\mathrm{HR}=0.83$; 95\% CI 0.42 to 1.64 ; Cohen's $d=0.65$ ). In the initial stages of glottis squamous cell carcinoma, treatment with transoral laser microsurgery shows a tendency for higher recurrence-free survival than treatment with radical radiotherapy in the first five years of intervention. Patients were not assigned randomly to the treatment, which might influence the generalization of our findings.
\end{abstract}

Corresponding author: Javier Santabárbara. Departamento de Microbiología, Pediatría, Radiología y Salud Pública. Universidad de Zaraǵoza. Zaragoza, España. Tel.: +34976551167. Email: jsantabarbara@unizar.es 


\title{
Comparación entre los tratamientos con radioterapia o con microcirugia láser transoral en pacientes en estadios tempranos de cáncer de glotis: un estudio de seguimiento por cinco años.
}

\author{
Invest Clin 2020; 61 (4): 324-334
}

Palabras clave: carcinoma de células escamosas glóticas; estadios tempranos; radioterapia; microcirugía transoral con láser; recurrencia; supervivencia.

Resumen. Este trabajo pretende comparar la tasa de supervivencia libre de recurrencia entre pacientes con carcinoma escamoso de la glotis en estadios I o II, tratados con microcirugía láser transoral o radioterapia, en un hospital Español de tercer nivel. Entre enero de 2004 y diciembre de 2016, se recopilaron datos de 120 pacientes diagnosticados con etapas I o II de carcinoma de células escamosas de la laringe localizada en la glotis. Noventa y un pacientes fueron tratados con microcirugía láser transoral y 29 pacientes recibieron radioterapia. La supervivencia libre de recurrencia se estudió durante los primeros cinco años después del tratamiento primario. Se realizaron curvas de supervivencia de Kaplan-Meier y modelos de regresión de Cox. La incidencia acumulada de recurrencia del cáncer de glotis fue del 62,6\% en los tratados con microcirugía láser transoral y del $65,5 \%$ en los tratados con radioterapia. Esto condujo a una reducción del riesgo absoluto del 2,9\% (IC del 95\%:-17,1 a 22,8) y un número necesario para tratar de 35 pacientes. Los pacientes que recibieron microcirugía transoral con láser tuvieron un riesgo 17\% menor de recurrencia del cáncer de glotis que los tratados con radioterapia (razón de riesgo, $\mathrm{HR}=0,83$; IC del 95\%: 0,42 a 1,64; d de Cohen =0,65). En las etapas iniciales del carcinoma glótico de células escamosas, el tratamiento con microcirugía láser transoral muestra una tendencia a una mayor supervivencia libre de recidivas que el tratamiento con radioterapia radical en los primeros cinco años de intervención. Los pacientes no fueron asignados aleatoriamente a un grupo de tratamiento, lo que podría afectar a la generalización de nuestros hallazgos.

Received: 05-08-2020 Accepted: 16-09-2020

\section{INTRODUCTION}

Squamous cell carcinoma (SCG) of the larynx is the most common malignant tumor of the head and neck (1). It is estimated that in 2018, approximately 39,900 new cases of laryngeal cancer were diagnosed in Europe, to which 19,600 deaths were attributed $(2,3)$. Approximately $50 \%$ of laryngeal cancer is lo- cated in the glottis(4), where it causes early dysphonia. At diagnosis, the majority of patients with SCC of glottis are in the initial stages of the disease (TI or TII), without regional lymph node metastasis (NO) or distance (M0). In fact, the incidence of clinically positive lymph nodes was almost $0 \%$ for $\mathrm{T} 1$ tumors and less than $2 \%$ for T2 (4). When diagnosed in the early stages and treated early, 
the prognosis is excellent (1) and complete healing can often be achieved (3).

Currently, the main treatment options for early glottic SCC (Stages I or II) are radiotherapy (RT) or surgical excision, both as a single treatment. Transoral laser microsurgery (TLM) is the most widely used surgical technique and has replaced the open techniques previously performed (5). It is currently accepted that both treatment modalities (RT and TLM) offer similar oncological results, as there is no evidence that one treatment is more effective than the other $(6,7)$. In any case, no randomized clinical trials have been published to date, and there are retrospective studies with results in favor of one treatment or the other. Therefore, the choice of treatment remains a controversial topic, and the decision usually depends on the experience of the team and the patient's preferences. In our institution, each specific case is presented to the Head and Neck Tumors Committee, composed of specialists in otolaryngology, medical oncology, radiation oncology, pathology and radiology. Usually, the first treatment option for Stages I or II of patients with glottic SCC in our hospital is TLM. If the patient presents comorbidities that pose a high surgical risk that contraindicates general anesthetic, or presents an anatomy that makes it difficult to perform the surgical intervention (cervical stiffness or difficult access to the larynx), the treatment with RT is chosen. It must be considered that treatment with TLM is more cost-effective than RT and represents lower hospital care costs. (8)

The objective of this study was to evaluate the recurrence-free survival of the disease after RT or TLM as a treatment of glottic cancer in early stages, to compare the effectiveness of both treatments.

\section{METHODS}

\section{Patients}

For this study, we identified patients diagnosed with glottic SCC in early Stages
I and II (T1 and T2, NO M0), who received treatment for the disease at the tertiary, "Lozano Blesa" Hospital (Zaragoza, Spain), either with TLM or RT, in the period between 2004 and 2016. Patients with laryngeal cancer at a location other than the glottis, or whose histological diagnosis was different from SCC, were excluded. Patients with other synchronous malignant tumors, patients treated by external partial surgery and those treated at other centers were also excluded. This study had been approved by the Ethic Committee of our hospital and was carried out in strict accordance with the Declaration of Helsinki (9).

\section{Data collection}

Data were collected from hospital medieal records. A total of 150 medical records of patients with larynx SCC located in the glottis were reviewed, of whom 30 subjects were rejected because they did not meet the inclusion criteria of the study, so that a sample of 120 patients was finally obtained. The collected variables included data on sociodemographic and behavioral factors, clinical findings, treatment, and the evolution of the disease.

\section{Treatment}

Patients who received radiotherapy were treated by a linear electron accelerator, externally, in three fields; with a radiation dose between 65 and $70 \mathrm{~Gy}$, and a fraction of 180$200 \mathrm{cGy} /$ session, completing the treatment with about 30 sessions. The patients who received surgical treatment were operated by TLM with a $\mathrm{CO}_{2}$ laser, performing different types of $\mathrm{CO}_{2}$ laser cordectomy depending on the tumor size and extension.

\section{Follow-up}

Once the treatment was started, the patient was closely monitored in a multidisciplinary way, through clinical examination and radiological study, depending on the evolution of the disease. After completing the treatment, a monthly clinical examina- 
tion was performed during the first year of follow-up. Subsequently, the reviews were distanced and an annual examination was performed with cervical computed tomography and chest radiography. If a possible tumor recurrence was suspected, specific radiological tests were requested, and biopsies of the lesion were performed if deemed necessary.

\section{Statistical analysis}

The statistical analysis and power calculation were carried out with IBM SPSS 22 and $\mathrm{G}^{*}$ Power (http://www.psychologie.hhu. de/arbeitsgruppen/allgemeine-psychologieund-arbeitspsychologie/gpower.html), respectively. The differences according to the type of primary treatment in the variables of the baseline study were evaluated through the Chi-Square test for the categorical variables and the Student $t$-test for the continuous ones. The normality of the quantitative variables was previously assessed using the Kolmogorov-Smirnov test.

In a first step of the analysis of the follow-up study, the cumulative incidences of recurrence of glottis cancer were calculated according to the type of primary treatment, to subsequently calculate the absolute risk reduction and the number needed to treat (NNT). Next, the odds of recurrence of glottis cancer were calculated according to the type of primary treatment. Subsequently, Kaplan-Meier survival curves were performed according to the type of primary treatment. In addition, the risk of recurrence of glottis cancer during follow-up was calculated according to the type of primary treatment using multivariate Cox regression models (10). To explore the mechanisms of association between the type of primary treatment and recurrence of glottis cancer, a series of models were used in which models were gradually controlled by potential confounders. The univariate model includes the type of primary treatment. The multivariate model additionally includes socio-demographic variables (gender and age), behavioral vari- ables (tobacco consumption and alcohol consumption) and clinical variables (tumor stage and location of the tumor lesion). To check the assumption of proportional risks, the Schoenfeld (11) residuals graph was used for the continuous variables and the log-log curves graph for the categorical variables. The effectiveness of the adjustments made using Cox regression models was evaluated with the Royston determination coefficient (12). Cohen's $d$ was calculated to document differences in glottis cancer recurrence risk according to the type of primary treatment. This coefficient measures the effect size and may be especially relevant in cases of small samples, when the differences found do not reach statistical significance (13). The effect size for the hazard ratio (HR) was classified as small $(\sim 0.2)$, medium $(\sim 0.5)$, or large ( 0.8) (14).

Finally, the calculation of the statistical power was performed to detect an HR (hazard ratio) of recurrence of glottis cancer associated with primary treatment in the population other than the unit.

\section{RESULTS}

\section{Description of patients and tumor characteristics}

After reviewing medical records, $150 \mathrm{pa}$ tients were selected for the study. Of these, 12 patients were excluded because they had an advanced stage of cancer during diagnosis, 9 patients with laryngeal SCC located in a different place than the glottis, 3 patients with histological diagnosis other than SCC, 4 patients for being treated by external partial surgery and 3 patients for being treated at other institutions. Finally, a sample of 120 patients with laryngeal SCC located in the glottis in Stages I or II was obtained, of whom 91 (75.8\%) received treatment with TLM and 29 (24.2\%) with RT.

The comparative results of the sociodemographic, behavioral, and clinical variables according to the type of treatment are shown in Table I. For sociodemographic vari-

Vol. 61(4): 324 - 334, 2020 
TABLE I

COMPARISON OF SOCIODEMOGRAPHIC, BEHAVIORAL AND CLINICAL VARIABLES IN THE BASELINE STUDY ACCORDING TO THE TYPE OF TREATMENT.

\begin{tabular}{|c|c|c|c|c|c|}
\hline \multirow{3}{*}{ VARIABLES } & \multicolumn{4}{|c|}{ TYPE OF PRIMARY TREATMENT } & \multirow[b]{3}{*}{$\mathrm{p}$} \\
\hline & \multicolumn{2}{|c|}{ RT $(\mathrm{N}=29)$} & \multicolumn{2}{|c|}{ TLM $(\mathrm{N}=91)$} & \\
\hline & Mean & $\mathrm{SD}$ & Mean & SD & \\
\hline Age & 63.9 & 10.8 & 62.3 & 11.4 & 0.512 \\
\hline & $\mathrm{N}$ & $\%$ & $\mathrm{~N}$ & $\%$ & $\mathrm{p}$ \\
\hline Gender & & & & & 0.111 \\
\hline Male & 29 & 100 & 82 & 90.1 & \\
\hline Female & 0 & 0 & 9 & 9.9 & \\
\hline Smoking status & & & & & 0.448 \\
\hline Non-smoker & 8 & 27.6 & 31 & 34.1 & \\
\hline$<=1$ packet $/$ day & 15 & 57.1 & 35 & 38.5 & \\
\hline$>1$ packet/day & 6 & 20.7 & 25 & 27.5 & \\
\hline Alcohol consumption & & & & & 0.381 \\
\hline Non consumer & 22 & 75.9 & 59 & 64.8 & \\
\hline Consumer & 7 & 24.1 & 32 & 35.2 & \\
\hline Tumoral stage & & & & & $<0.001$ \\
\hline $\mathrm{I}$ & 18 & 62.1 & 84 & 92.3 & \\
\hline II & 11 & 37.9 & 7 & 7.7 & \\
\hline Location of the tumor & & & & & $<0.001$ \\
\hline Only one vocal cord & 11 & 37.9 & 84 & 92.3 & \\
\hline Both vocal cords & 5 & 17.2 & 3 & 3.3 & \\
\hline Anterior commissure involvement & 13 & 44.8 & 4 & 4.4 & \\
\hline
\end{tabular}

RT: radiotherapy; TLM: transoral laser microsurgery; SD: Standard deviation.

ables such as age and gender, there were no statistically significant differences between the treatment groups; the mean age was 63.9 years in the group of patients treated with RT, and 62.3 in the TLM group. The majority of patients included in the study were men (100\% of patients in the RT group, and $90.1 \%$ in the TLM group). Nor were there significant differences between the two groups regarding the consumption of tobacco and alcohol. In both groups, the majority of patients were smokers $(72.4 \%$ of patients in the RT group and $65.9 \%$ in the TLM group).
On the other hand, there were group differences in terms of tumor stage ( $p<$ $0.001)$. In the group of patients treated with RT, 18 patients (62.1\%) were in Stage I, and 11 patients (37.9\%) were in Stage II. However, the majority of patients treated with TLM (84 patients, 92.3\%) were in Stage I, compared to seven patients (7.7\%) who were in Stage II. Regarding the location of the tumor, in the RT group, $44.8 \%$ of the patients presented a lesion that affected the anterior commissure $(\mathrm{p}<0.001)$. In the group of patients treated with TLM, the majority 
(92.3\%) had a tumor confined to a single vocal cord, and only in $4.4 \%$ was the anterior commissure affected.

\section{Survival analysis}

The 120 patients included in the study were monitored for a maximum of five years, and cancer recurrence was analyzed in the patients of each treatment group (Tables II and III). The cumulative incidence of recurrence of glottis cancer at the end of the follow-up was $62.6 \%$ in those treated with TLM and $65.5 \%$ of those treated with RT, resulting in an absolute risk reduction of 2.9\% (95\% CI -17.1 to 22.8) and a number needed to treat (NNT) of 35 patients (data not shown). The odds of recurrence of glottis cancer was $12 \%$ lower in the group of patients treated with TLM (Odds ratio $=0.88 ; 95 \%$ CI 0.35 to 2.11) compared to the group of patients treated with RT (Table II). Given that the 95\% CI for the Odds ratio contains the null value $(\mathrm{OR}=1)$, the differences in the probability of recurrence of glottis cancer between the two treatments did not reach statistical significance $(\mathrm{p}=0.792)$.

\section{TABLE II}

INCIDENCE RATE (PER 1.000 PERSON PER YEAR) AND INCIDENCE RATE RATIO OF RECURRENCE OF GLOTTIS CANCER ACCORDING TO THE TYPE OF PRIMARY TREATMENT.

\begin{tabular}{lccc}
\hline $\begin{array}{l}\text { Primary } \\
\text { treatment }\end{array}$ & $\begin{array}{c}\text { Incident } \\
\text { cases, n (\%) }\end{array}$ & OR & $95 \%$ CI \\
\hline RT $(\mathrm{n}=29)$ & $19(65.5)$ & 1 & - \\
TLM $(\mathrm{n}=91)$ & $57(62.6)$ & 0.88 & $(0.35-2.11)$ \\
\hline
\end{tabular}

RT: radiotherapy; TLM: transoral laser microsurgery; OR: Odds ratio; CI: confidence interval.

The mean survival time for recurrence of glottis eancer of the patients in the study was 37.2 months (95\% CI: 33.4 to 41.2 ). Specifically, in the group of patients treated with TLM, it was 38.8 months (95\% CI: 34.5 to 43.1 ) versus 32.5 months (95\% CI: 23.9 to 41.1) of those patients treated with RT (Fig. 1). The comparison of survival curves according to the type of treatment shows that, after five years of follow-up, the probability of surviving recurrence of glottis cancer is higher in patients who received TLM (Tarone-Ware test: $\mathrm{p}=0.265$ ), although it did not reach statistical significance.

Univariate and multivariate Cox regression analysis were performed for recurrence of glottis cancer as shown in Table III. In the unadjusted (univariate) model, those patients treated with TLM had a 20\% lower risk of recurrence of glottis cancer than those treated with RT (hazard ratio, $\mathrm{HR}=0.80$; $95 \%$ CI 0.47 to 1.34 ). The risk found did not reach statistical significance $(\mathrm{p}=0.397)$. The assumption of proportional hazards over the follow-up time of the categorical variable "type of primary treatment" was verified by visual inspection of the log-log curves of the univariate model (Fig. 2). As both curves are approximately parallel, we conclude that the HR of the variable "type of primary treatment" remained constant throughout the follow-up time.

When adjusting the model for the rest of the sociodemographic characteristics (gender and age), behavioral variables (tobaceo and alcohol consumption), and clinical variables (tumor stage and location of the tumor lesion), those patients treated with TLM had a $17 \%$ lower risk of cancer recurrence of glottis than those treated with RT (hazard ratio, HR $=0.83 ; 95 \%$ CI 0.42 to 1.64), once the effect of potential confounders and/or modifiers of the effect was controlled $(p=0.586)$. This effect did not reach statistical significance in the multivariate model (power $=0.173$ ), but its magnitude was considered medium (Cohen's $d=0.65$ ).

By visual inspection of the log-log curves of the fully adjusted model (Fig. 2B), the assumption of proportional hazards over the follow-up time of the categorical variable "type of primary treatment" was verified. Given that both curves are approximately parallel, we conclude that, once the effect of the rest of the covariates of the multivariate model on the risk of recurrence of glottis 


\section{TABLE III}

COX REGRESSION OF RECURRENCE OF GLOTTIS CANCER ACCORDING TO THE TYPE OF PRIMARY TREATMENT.

\begin{tabular}{ccccc}
\hline \multicolumn{5}{c}{ Disease recurrence } \\
\hline Primary treatment & Univariate Model & \multicolumn{2}{c}{ Multivariate Model } \\
\hline \multirow{2}{*}{ RT } & HR $(95 \% \mathrm{CI})$ & $\mathrm{p}$ & HR $(95 \% \mathrm{CI})$ & $\mathrm{p}$ \\
TLM & 1 & 0.397 & 1 & 0.586 \\
& 0.80 & & 0.83 & \\
\hline
\end{tabular}

RT: radiotherapy; TLM: transoral laser microsurgery; CI: confidence interval; HR: Hazard ratio.

Multivariate Model included terms for sociodemographic variables (gender and age), behavioral variables (tobacco consumption and alcohol consumption) and clinical variables (tumor stage and location of the tumor lesion).

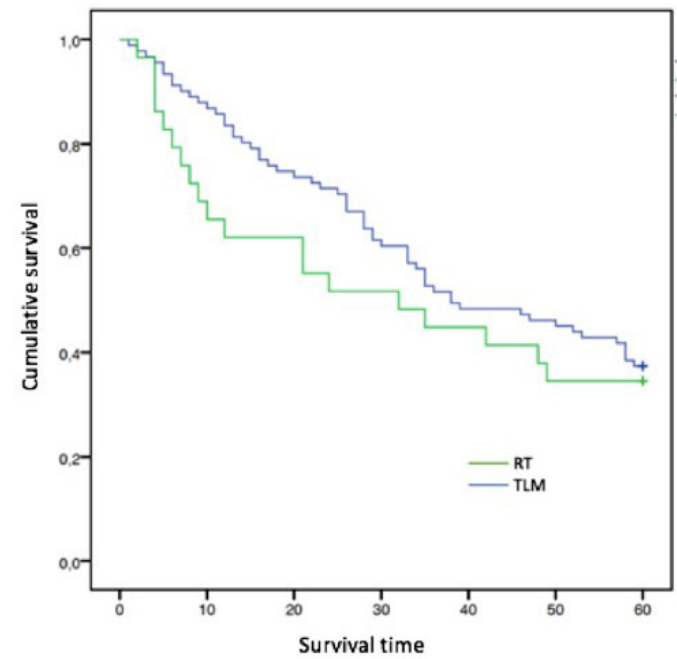

Fig. 1. Recurrence-free survival curves according to the type of treatment.
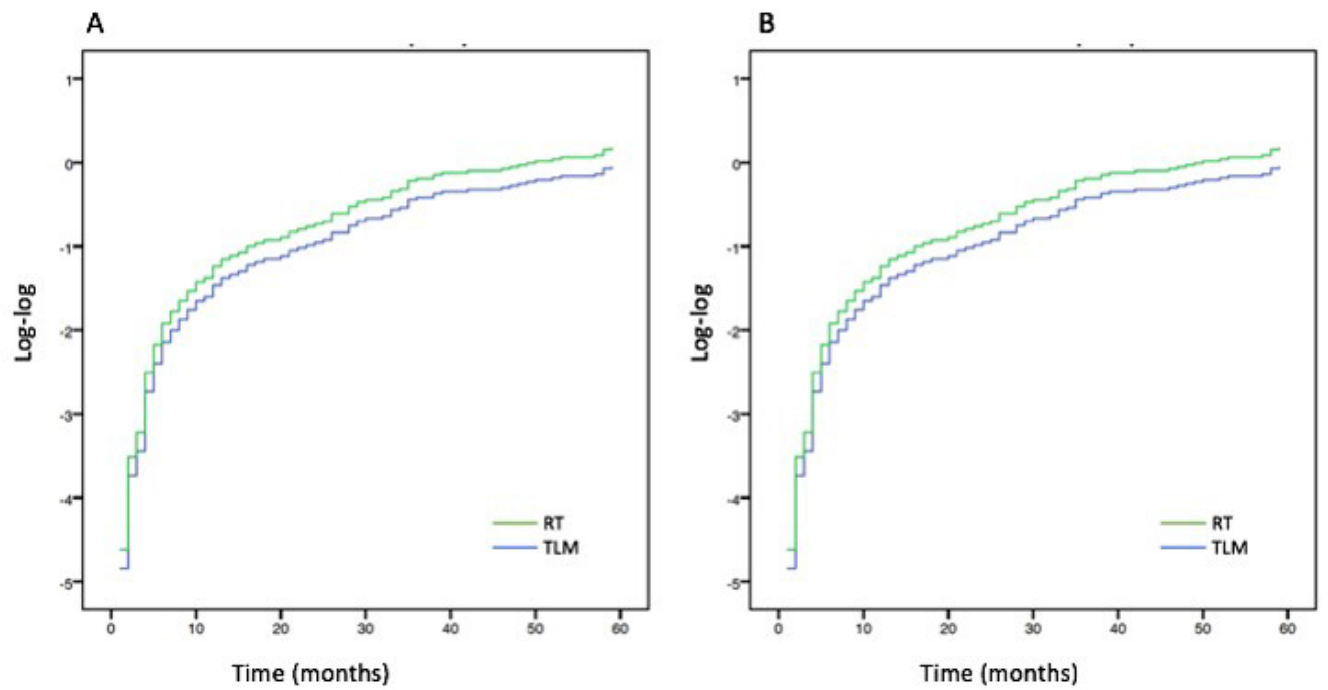

Fig. 2. Log-log survival curves according to the type of treatment. A: Univariate model; B: multivariate model, adjusted by sociodemographic, behavioral, and clinical variables. 
cancer was controlled, the HR of the variable "type of primary treatment" remained constant throughout the follow-up period.

To quantify the goodness of fit of the multivariate model, the Royston determination coefficient was calculated, obtaining a value of 0.15 . That is to say, $15 \%$ of the variability of the survival time to recurrence of glottis eancer of the patients under study is explained by the variable "type of primary treatment" and by the rest of the adjustment variables.

\section{DISCUSSION}

The sociodemographic characteristics of the patients in our study are consistent with the published literature on laryngeal SCC. The mean age at the time of diagnosis was 63 years, and a male predominance was observed, with a male: female ratio of 12.3 : 1. Likewise, we observed the relationship between the appearance of laryngeal cancer and tobacco consumption, as $67.5 \%$ of the patients included in the study were smokers, or had been smoking in the 10 years prior to diagnosis (15-17).

There are no randomized controlled clinical trials to verify possible differences in the survival of glottis cancer in early stages between the two primary treatment alternatives. As different published systematic reviews and meta-analyses reflect, the majority are case series and comparative retrospective studies. This work is retrospective, and it compares recurrence-free survival of glottis cancer in early stages based on the type of treatment patients receive to determine treatment effectiveness, as in similar reviewed studies.

This study presents the limitations typical of retrospective studies. The patients were not assigned randomly to the treatment groups but were given the treatment that the clinical team considered most appropriate for each case, which is why the group of patients treated with TLM is larger than those treated with RT (75.8\% vs. $24.2 \%)$. This might have influenced the results and, therefore, the generalization of our findings. However, this imbalance between the number of patients in the treatment groups have occured in previous retrospective studies. Currently, most of the early-stage squamous cell carcinomas of glottic area are treated with TLM. To avoid this limitation, future studies should use propensity score matching.

The greater the extent of the tumor, the greater the difficulty presented for its surgical resection. Some patients have an exposure of the glottis area that is very difficult to access with the laryngoseope; in these cases, the best treatment option is RT because, with TLM, there could be near or positive margins (18). For this reason, the study shows that patients treated with RT were at a higher stage of cancer. Of the 18 patients in Stage II, 11 patients (61.1\%) were treated with RT, compared with the remaining seven patients (38.8\%), who were treated with TLM. However, most of the patients in Stage I (84 patients out of 102, that is, $82.3 \%$ ) were treated with TLM, compared with $17.6 \%$ of patients in Stage I, who were treated with RT.

Something similar occurs concerning the tumor location, as tumors located in the anterior commissure offer an added difficulty to resection, because this area is sometimes difficult to access with the laryngoscope and, therefore, to influence with the laser and perform a resection with safety margins. In addition, it is recently accepted that tumors that affect the anterior commissure are more likely to progress or recur due to the characteristics of this area $(19,20)$, which facilitate the spread of cancer cells because the cartilaginous barrier is weaker at this location. This is why, in patients whose tumor originates at the anterior commissure, we favor treatment with RT, as can be seen in our work, given that of the 17 patients who had affectation in the anterior commissure, 13 (76.4\%) received RT, compared to the 4 patients $(23.5 \%)$ who were treated with TLM. 
According to the results of our study, after five years of follow-up, the probability of surviving the recurrence of glottis cancer is higher in patients treated with TLM than in those treated with RT. Although this did not reach statistical significance in the multivariate model, the effect size could be considered medium. Specifically, the mean survival time for glottis cancer to recur in patients treated with TLM was 38.8 months versus 32.5 months of those patients treated with RT. In the multivariate Cox regression model, once the confounding effect of the sociodemographic, behavioral, and clinical variables was eliminated, those patients who received TLM had a $17 \%$ lower risk of recurrence of glottis cancer than those treated with RT. The sensitivity analysis support this finding. In the literature published on this subject, there are different results in favor of one type of treatment to another. The results of this work coincide with those obtained in a study of a similar methodology by De Santis et al. (21), in which no difference in disease-free survival was demonstrated between the two treatment groups after stratification by confounding variables.

However, other retrospective studies such as the recent publications of Chung et al. (22) and Shelan et al. (23) obtained better oncological results with RT compared to TLM. A meta-analysis published in 2018 by Guimaraes et al. (24) on the treatment in $\mathrm{T} 1$ of glottis concludes that patients initially treated with TLM have a longer general and specific survival than those treated with RT. However, in the majority of systematic reviews (25-27) and meta-analyses (28-32) published to date, there are no statistically significant differences in terms of overall and specific disease survival between the two treatment modalities.

One of the future lines of research of this workgroup is to collect information on the quality of life and voice quality of patients after RT or TLM, as well as to assess the economic cost of each treatment (8). Both aspects are important, considering that most of the previous publications agree that neither of the therapeutic options obtained better oncological results, and can guide the choice of treatment.

As a conclusion, TLM in the early stages (I or II) of treatment of patients with glottic SSC, offers greater survival to the recurrence of the disease compared to the treatment with radical RT. However, this finding did not reach statistical significance. Both treatments obtained good oncological results, so multicenter studies and meta-analyses are needed to reach stronger conclusions that facilitate the choice of one treatment or the other.

\section{ACKNOWLEDGEMENTS}

The author is grateful to José Miguel Sebastián, Félix de Miguel, Fernando García and Yolanda Lois from "Lozano Blesa" Hospital for their contribution and support.

\section{REFERENCES}

1. Quer Agustí M, López Vila M. Clinical characteristics of laryngeal tumors. In: Suárez Nieto G, director and general coordinator. Treaty of Otolaryngology and Head and Neck Surgery, volume IV: Oncological surgery of the head and neck and the skull base. 2nd ed. Madrid: Editorial Médica Panamericana, S.A. 2009.

2. Bray F, Ferlay J, Soerjomataram I, Siegel RL, LA Tower, Jemal A. Global cancer statistics 2018: GLOBOCAN estimates of incidence and mortality worldwide for 36 eancers in 185 countries. CA Cancer J Clin 2018; 68: 394-424. doi:10.3322/ caac. 21492.

3. Ferlay J, Colombet M, Soerjomataram I, Dyba T, Randi G, Bettio M, Gavin A, Visser O, Bray F. Cancer incidence and mortality patterns in Europe: Estimates for 40 countries and 25 major cancers in 2018. Eur J Cancer 2018; 103: 356-387. doi: 10.1016 / j.ejca. 2018.07.005

4. Shah J, Patel S. Larynx and trachea. In: Shah J, director and general coordinator. Head and Neck Surgery and Oncology. 5th ed. Madrid: Elsevier España, S.A.; 2020. 
5. Canis M, Ihler F, Martin A, Matthias C, Steiner W. Transoral laser microsurgery for T1a glottic cancer: review of 404 cases. Head Neck 2015;37:889-895. doi:10.1002/ hed.23688.

6. National Comprehensive Cancer Network. Head and Neck Cancers (Version 2.2018). http://www.ncen.org/professionals/physician_gls/pdf/head-and-neck.pdf.

7. Iglesias Docampo LC, Arrazubi Arrula V, Baste Rotllan N, Carral Maseda A, Cirauqui Cirauqui B, Escobar Y, Lambea Sorrosal JJ, Pastor Borgononón M, Rueda A, Cruz Hernández JJ. SEOM clinical guidelines for the treatment of head and neck cancer (2017). Clin Transl Oncol 2018; 20: 75-83. doi: 10.1007 / s12094-017-1776-1.

8. Diaz-de-Cerio P, Preciado J, Santaolalla F, Sanchez-Del-Rey A. Cost-minimisation and cost-effectiveness analysis comparing transoral $\mathrm{CO}_{2}$ laser cordectomy, laryngofissure cordectomy and radiotherapy for the treatment of T1-2, NO, MO glottic carcinoma. Eur Arch Otorhinolaryngol 2013;270:1181-1188. doi:10.1007/s00405012-2139-8.

9. World Medical Association I. Declaration of Helsinki: ethical principles for medical research involving human subjects. J Indian Med Assoc 2009;107:403-405.

10. Cox DR. Reǵression models and life tables. Journal of the Royal Statistical Society: Series B (Statistical Methodology). 1972; 34:187-220.

11. Schoenfeld D. Partial Residuals for The Proportional Hazards Regression Model. Biometrika. 1982; 69 (1):239-241.

12. Royston P. Explained variation for survival model. The Stata Journal 2006; 6:83-96.

13. Cohen J. Statistical Power Analysis for the Behavioral Sciences, 2nd ed. Hillsdale, NJ: Lawrence Erlbaum Associates; 1988.

14. Azuero A. A note on the magnitude of hazard ratios. Cancer 2016; 122: 1298-1299.

15. Jethwa AR, Khariwala SS. Tobacco-related carcinogenesis in head and neck cancer. Cancer Metastasis Rev 2017;36:411-423. doi:10.1007/s10555-017-9689-6.

16. León X, López M, García J, Montserrat JR, Gras JR, Kolanczaka KA, Quer M. Características epidemiológicas de los pacientes con carcinomas escamosos de cabeza y cue- llo. Resultados de un registro hospitalario. Acta Otorrinolaringol Esp 2019;70:272278 https://doi.org/10.1016/j.otorri.2018. 05.006 .

17. Kawakita D, Matsuo K. Alcohol and head and neck cancer. Cancer Metastasis Rev 2017;36:425-434. doi:10.1007/s10555-017 -9690-0.

18. Tirelli G, Gatto A, Fortunati A, Marzolino R, Giudici F, Boscolo Nata F. Predicting laryngeal exposure in microlaryngoscopy: External validation of the laryngoscore. Laryngoscope 2019;129:1438-1443. doi:10.1002/lary.27683.

19. Hakeem AH, Tubachi J, Pradhan SA. Siǵnificance of previous commissure involvement in early glottic squamous cell carcinoma treated with transoral $\mathrm{CO}_{2}$ laser microsurgery. Larynǵoscope 2013; 123 : 1912-1917.

20. Alkan U, Nachalon Y, Shkedy Y, Yaniv D, Shvero J, Popovtzer A. T1 squamous cell carcinoma of the glottis with anterior commissure involvement: Radiotherapy versus transoral laser microsurgery. Head neck 2017; 39: 1101-1105. doi: $10.1002 /$ hed. 24723.

21. De Santis RJ, Poon I, Lee J, Karam I, Enepekides DJ, Higgins KM. Comparison of survival between radiation therapy and transoral laser microsurgery for early glottic cancer patients; a retrospective cohort study. J Otolaryngol Head Neck Surg 2016; 45: 42.

22. Chung SY, Kim KH, Keum KC, Koh YW, Kim SH, Choi EC, Lee CG. Radiotherapy versus cordectomy in the management of early ǵlottic cancer. Cancer Res Treat 2018; 50: 156-163. doi: 10.4143/crt. 2016.503.

23. Shelan M, Anschuetz L, Schubert AD, Bojaxhiu B, Dal Pra A, Behrensmeier F, Aebersold DM, Giger R, Elicin O. T1-2 glottic cancer treated with radiotherapy and / or surgery. Strahlenther Onkol 2017; 193: 995-1004. doi: 10.1007 / s00066-0171139-4.

24. Guimarães AV, Dedivitis RA, Matos LL, Aires FT, Cernea CR. Comparison between transoral laser surgery and radiotherapy in the treatment of early glottic cancer: A systematic review and meta-analysis. Sci Rep 2018; 8: 11900. doi: 10.1038 / s41598-01830218- $x$.

Vol. 61(4): 324 - 334, 2020 
25. Yoo J, Lacchetti C, Hammond JA, Gilbert RW; Head and Neck Cancer Disease Site Group. Role of endo laryngeal surgery (with or without laser) versus radiotherapy in the management of early (T1) glottic cancer: a systematic review. Head neck 2014; 36: 1807-1819. doi: 10.1002 / hed.23504.

26. Warner L, Lee K, Homer JJ. Transoral laser microsurgery versus radiotherapy for T2 glottic squamous eell carcinoma: a systematic review of local control outeomes. Clin Otolaryngol 2017; 42: 629-636. doi: 10.1111 / coa.12790.

27. Sjögren EV. Transoral laser microsurgery in early golottic lesions. Curr Otorhinolaryngol Rep 2017; 5: 56-68. doi: 10.1007 / s40136017-0148-2.

28. Gioacchini FM, Tulli M, Kaleci S, Bondi S, Bussi M, Re M. Therapeutic modalities and oncologic outcomes in the treatment of T1b glottic squamous eell carcinoma: a systematic review. Eur Arch Otorhinolaryngol 2017; 274: 4091-102. doi: 10.1007/ s00405-017-4736-\%.
29. Mendenhall WM, Werning JW, Hinerman RW, Amdur RJ, Villaret DB. Management of T1-T2 glottic carcinomas. Cancer 2004; 100: 1786- 1792.

30. Abdurehim Y, Hua Z, Yasin Y, Xukurhan A, Imam I, Yuqin F. Transoral laser surgery versus radiotherapy: systematic review and meta-analysis for treatment options of T1a glottic eancer. Head neck 2012; 34: 23-33. doi: 10.1002 / hed.21686.

31. Mo HL, Li J, Yang $X$, Zhang $F$, Xiong JW, Yang ZL, Tan J, Li B. Transoral laser microsurgery versus radiotherapy for T1 glottic carcinoma: a systematic review and metaanalysis. Lasers Med Sci 2017; 32: 461-467.

32. Huang G, Luo M, Zhang J, Liu H. Laser surgery versus radiotherapy for Tla ǵlottic carcinoma: a meta-analysis of oncologic outeomes. Otolaryngol Act 2017; 137: 1204-1209. doi: 10.1080/00016489.2017.1353706. 